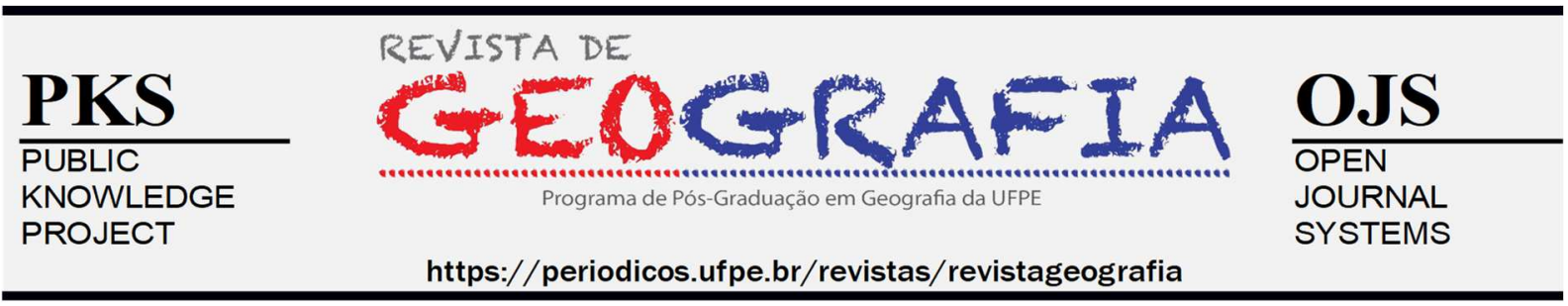

\title{
CARACTERIZAÇÃO DE ZONAS CLIMÁTICAS LOCAIS NA CIDADE DE SANTA MARIA - RIO GRANDE DO SUL
}

\author{
Bruna Zambonato ${ }^{1}$, Kananda Fernandes de Sousa Lima $^{2}$, Paula Maronesi Lehr ${ }^{3}$, Renata \\ Serafin de Albernard ${ }^{4}$, Giane de Campos Grigoletti ${ }^{5}$
}

\begin{abstract}
1 Arquiteta e Urbanista mestranda do Programa de Pós-Graduação em Arquitetura, Urbanismo e Paisagismo da Universidade Federal de Santa Maria, zambonato.bruna@gmail.com, ORCID: http://orcid.org/0000-0001-73512259

2 Arquiteta e Urbanista mestranda do Programa de Pós-Graduação em Arquitetura, Urbanismo e Paisagismo da Universidade Federal de Santa Maria, kananda_lima@hotmail.com, ORCID: http://orcid.org/0000-0002-17264665

${ }^{3}$ Arquiteta e Urbanista graduada na Universidade Federal de Santa Maria, paulamaronesilehr@gmail.com, ORCID: http://orcid.org/0000-0002-2794-8008

${ }^{4}$ Arquiteta e Urbanista mestranda do Programa de Pós-Graduação em Arquitetura, Urbanismo e Paisagismo da Universidade Federal de Santa Maria, renata.albernard@gmail.com, ORCID: http://orcid.org/ 0000-0002-10911735

${ }^{5}$ Doutora, Professora do Departamento de Arquitetura e Urbanismo, Universidade Federal de Santa Maria, giane.c.grigoletti@ufsm.br, ORCID: http://orcid.org/0000-0002-0696-2062
\end{abstract}

Artigo recebido em 11/05/2020 e aceito em 05/05/2021

\begin{abstract}
RESUMO
O clima urbano é composto por um mosaico de microclimas que, numa escala local, influenciam de maneiras diferentes as variáveis temperatura, umidade do ar, ventos, dentre outras. O estudo buscou contribuir para o entendimento e caracterização do clima urbano, sob os efeitos da urbanização, para a cidade de Santa Maria, RS. O método utilizou a classificação de zonas climáticas locais (ZCL) e foi composto pela definição das áreas de estudo, levantamento das variáveis de ocupação urbana, e caracterização das áreas quanto a ocupação urbana e densidade construída. Foram definidas quatro áreas de estudo, com padrões de ocupação urbana distintos. Os resultados demonstraram variação significativa das características analisadas nas áreas. A densidade construída mostra que a cidade de Santa Maria ainda não possui uma verticalização acentuada. Como previsto, há relação direta entre a proporção de vegetação e edificações: zonas com maior superfície vegetal apresentaram menor porcentagem de edificações. Os resultados apontam a importância do planejamento urbano, sendo a área de menor densidade construída $(33,19 \%)$ em loteamento residencial planejado, afastado do centro. Espera-se que os resultados auxiliem na classificação das ZCL, para maior entendimento dos efeitos das Ilhas de Calor e proposição de estratégias que melhorem as condições climáticas urbanas.
\end{abstract}

Palavras-chave: zonas climáticas locais; Santa Maria; cobertura do solo. 


\title{
CHARACTERIZATION OF LOCAL CLIMATE ZONES IN THE CITY OF SANTA MARIA - RIO GRANDE DO SUL
}

\begin{abstract}
The urban climate is composed of a group of microclimates that, on a local scale, influences in different ways variables such as air temperature, air humidity, wind speed, among others. The study aims to contribute to the understanding and characterization of urban climate, under the effects of urbanization, in Santa Maria, RS. The method used the local climate zone (LCZ) classification and was composed of the definition of the study areas, survey of the urban occupation variables and characterization of the areas, regarding the urban occupation and built density. Four study areas were defined, with different urban occupation patterns. Results showed significant variation of characteristics between zones. The built density shows that the city does not have a strong verticalization. As predicted, there is a direct relationship between the proportion of vegetation and buildings: zones with larger vegetation surface present a lower percentage of buildings. Results point to the importance of urban planning, being the area with the lowest built density $(33.19 \%)$ a planned residential neighborhood, away from the city centre. The data presented could assist the classification of LCZ, enabling a better understanding of the Urban Heat Islands effects and facilitate the proposition of strategies to improve urban climate conditions.
\end{abstract}

Keywords: local climate zones; Santa Maria; land cover.

\section{INTRODUÇÃO}

O processo de urbanização é um processo mundial. Segundo a Organização das Nações Unidas (UN, 2019), até 2030, 60,4\% da população viverá em cidades. No Brasil, segundo resultados da Pesquisa Nacional por Amostra de Domicílios, em 2015, 84,72\% da população vivia em áreas urbanas (IBGE, 2020). Em contrapartida, as áreas urbanas ocupavam 0,63\% do território nacional, concentrando mais de 160 milhões de pessoas (EMBRAPA, 2017). Esses dados demonstram o impacto das cidades, com grande densidade demográfica, sobre o ambiente natural. Esse fenômeno causa a intensificação da degradação ambiental em áreas urbanas, principalmente pela substituição de áreas com cobertura vegetal e permeáveis, por superfícies rígidas e com grande capacidade de retenção de calor.

A substituição das superfícies vegetais causada pela urbanização sem planejamento adequado é uma das principais responsáveis pelas alterações climáticas nas cidades. A retirada da cobertura vegetal altera significativamente as propriedades da superfície e modifica o balanço hídrico local em razão da redução da evapotranspiração das plantas e do escoamento superficial. O balanço de radiação também sofre alterações pela nova constituição da volumetria das construções e pelo albedo das superfícies (OKE, 1987, MIRZAEI, 2015). 
As propriedades térmicas dos edifícios, a densidade construtiva e a redução da evaporação podem ser consideradas fatores determinantes na alteração da temperatura, da umidade e dos ventos no meio urbano. Além disso, essas alterações também são resultado das atividades exercidas pelos seres humanos, como atividades industriais, emissão de poluentes na atmosfera, tráfego de veículos, dentre outros (OKE, 1979).

Todos esses fenômenos contribuem para a formação de microclimas em diferentes zonas da cidade. O conjunto dos microclimas, quando associados, representam um clima específico, denominado clima urbano (ROSSI; KRÜGER, 2015). Alguns fenômenos diretos e indiretos dessa alteração climática são o desconforto térmico, maior consumo de energia para climatização artificial de edificações, menor umidade do ar, diminuição da velocidade da ventilação natural, aumento da capacidade térmica e queda da evapotranspiração (NUCCI, 2008; DUARTE et al., 2015). Oke (2006) evidencia a necessidade de avaliação da estrutura urbana, da cobertura da superfície, do tecido e do metabolismo urbanos para se compreender o efeito da urbanização na camada de ar contida entre as edificações, chamada dossel urbano, e consequentemente, no clima local.

Stewart e Oke $(2009,2012)$ apontam a simplificação excessiva de considerar o clima urbano como simplesmente uma oposição ao clima rural. O clima urbano é composto por um mosaico de microclimas que, numa escala local, influenciam de maneiras diferentes as variáveis temperatura, umidade do ar, vento, dentre outras. A variabilidade está associada aos diferentes tipos de pavimentos, à presença ou à ausência de vegetação e água, à altura das edificações, à largura das vias, às atividades antrópicas e à extensão dessas áreas relativamente homogêneas. Combinados, os microclimas dão origem ao clima urbano como um todo.

A partir da compreensão desse fenômeno, Stewart e Oke (2012) desenvolveram um sistema de classificação das paisagens urbanas e rurais dividido em 19 zonas climáticas locais (ZCL), as quais derivam de uma divisão da paisagem em subclasses diferenciadas de acordo com as características do cobrimento do solo (edificações, pavimentos, albedo, fator de céu visível, rugosidade e fatores antropogênicos) (STEWART; OKE, 2009). Dentre as 19 ZCL, 10 são relacionadas aos tipos de ocupação do solo por edificações e 7 referem-se aos tipos de cobertura de solo. Foram estabelecidas, também, uma classe para uso industrial e quatro subdivisões para caracterizar propriedades sazonais de cobertura de solo (Figura 1). 
FIGURA I - SISTEMA DE CLASSIFICAÇÃO DAS PAISAGENS URBANAS E RURAIS.

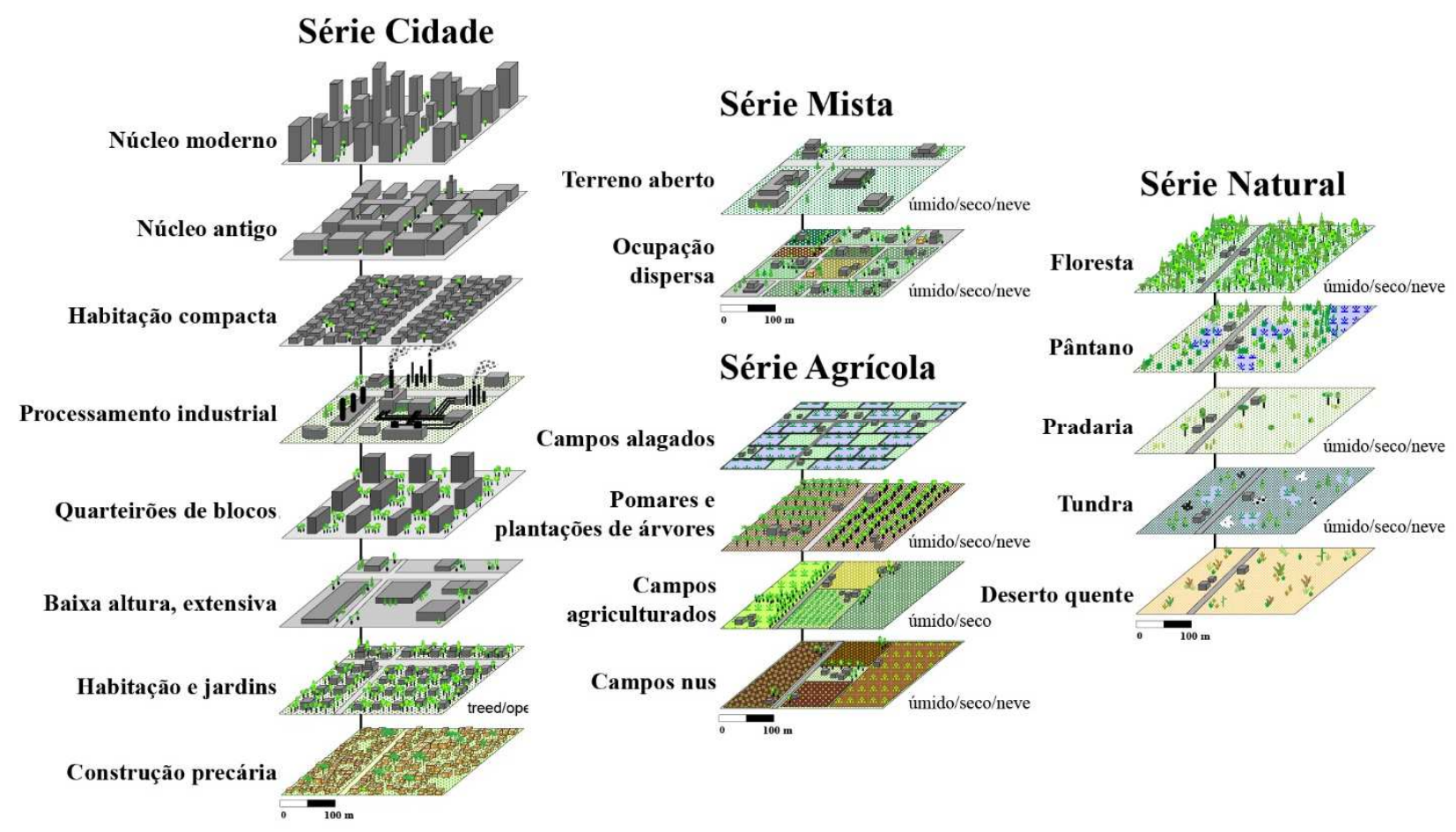

Fonte: Adaptado de STEWART; OKE (2009)

Zonas climáticas locais se tornaram um parâmetro internacional de identificação da morfologia urbana e de seus impactos na temperatura local (WANG, et al., 2018). A análise de zonas climáticas permite identificar a contribuição negativa do processo de ocupação e sua alteração no microclima urbano. O método desenvolvido por Stewart e Oke, desde 2009, vem sendo usado em diversos estudos do clima urbano e do efeito de ilha de calor com diferentes objetivos. Danylo et al. (2016) e Betchel et al. (2015) esclarecem que o conhecimento da divisão das cidades em suas ZCL colabora de diversas formas para o planejamento urbano.

Os autores citam modelos de prevenção de desastres ambientais, como a alteração do padrão de precipitação, definição de pontos de coleta de dados meteorológicos intraurbanos, como temperatura e umidade do ar, para desenvolver modelos climáticos, estudos do efeito de ilha de calor e caracterização da forma urbana a partir de uma metodologia padronizada. Em relação a esta metodologia padrão, Danylo et al. (2016) e Betchel et al. (2015) citam o programa World Urban Database and Acess Portal Tools (WUDAPT) como um esforço em disponibilizar dados mundiais detalhados sobre as várias características de ocupação urbana, incluindo as culturais, com influência relevante no efeito de ilha de calor. A partir desses dados, busca-se o refinamento de ferramentas e 
o compartilhamento de experiências e conhecimento a fim de propiciar um planejamento urbano que possa solucionar, prever e mitigar os efeitos negativos da urbanização em escala mundial.

No contexto brasileiro, desde os anos 1970, existem estudos que procuram analisar e explicar a origem e os efeitos do clima urbano, assim como propor ações preventivas ou de mitigação (TARIFA, 1977; LOMBARDO, 1985; MENDONÇA, 1994; PITTON, 1997; AMORIM, 2000, 2010; DUMKE, 2007; ALVES; SPECIAN, 2010; ROCHA; SOUZA; CASTILHO, 2011; UGEDA JÚNIOR, 2012; SANTOS, 2013; DUARTE et al., 2015; BRÚSSOLO; ELY, 2015; FIALHO; CELESTINO; QUINA, 2016; GRIGOLETTI; LAZAROTTO; WOLLMANN, 2018, FIALHO, FERNANDES, CORREA, 2019; SANTOS, 2020). Os estudo citados concentram-se em cidades de diferentes portes e usam diferentes metodologias para levantamentos e análises, como medições em transecto móvel e medições fixas. Os autores apontam tanto a importância das variáveis de uso e ocupação do solo, quanto a presença de áreas vegetadas nas cidades como principais elementos de controle do clima urbano, independente do porte urbano estudado.

Rocha, Souza e Castilho (2011), ao analisarem a influência da morfologia urbana na temperatura do ar ao longo de avenidas na cidade de São José do Rio Preto, SP, cidade de porte médio, com cerca de 465 mil habitantes, basearam-se em dados da morfologia urbana obtidos de imagens de satélite e observações de campo. Os autores apontaram a influência dessas variáveis nas temperaturas noturnas e seu papel dominante para as ilhas de calor urbanas nesse período. Santos (2013), para Cuiabá, MT, com 620 mil habitantes, por meio de transectos móveis noturnos para medição de temperatura e umidade do ar, também demonstrou que o uso e a ocupação do solo, com a supressão da vegetação, foram determinantes para as diferenças observadas nas temperaturas medidas. A autora observou que áreas com grandes massas de vegetação possuem um comportamento próprio e favorável ao controle de altas temperaturas.

Brússolo e Ely (2015), para a cidade de Assis, SP, com 95 mil habitantes, cidade de pequeno porte, também usaram o mapeamento do uso e ocupação do solo, baseando-se em imagens de satélite e observações de campo para estudar a sua influência nas temperaturas urbanas. Os autores concluíram que, mesmo para uma pequena cidade como Assis, o adensamento e a vegetação foram elementos determinantes na formação de ilhas de calor. Mesma conclusão de Alves e Specian (2010), que investigaram o comportamento da temperatura e da umidade do ar em Iporá, GO, com 32 mil habitantes. Ali também verificaram que a ocupação urbana, como superfícies pavimentadas 
ou revestidas de vegetação, foi capaz de criar microclimas, não na mesma magnitude de uma grande cidade, mas perceptível, indicando a importância do planejamento urbano considerar tais fenômenos, independente do porte da cidade.

Fialho, Celestino e Quina (2016), para Cajuri, MG, cidade de pequeno porte, com cerca de 4 mil habitantes, usaram a técnica de transecto móvel para medições da temperatura e constataram que há diferenças de temperatura entre o centro da cidade urbanizando e seus arredores, mesmo para um sítio urbano de pequena área como Cajuri, com pouca densidade construída e verticalização. Santos (2020), para Goiânia, GO, cidade de grande porte, com cerca de 1,5 milhão de habitantes, como era esperado, também demonstrou a influência das variáveis de uso e ocupação do solo sobre a temperatura e a umidade do ar. $\mathrm{O}$ autor fez a caracterização das áreas de estudos conforme a classificação em zonas climáticas locais e confirmou que parques intraurbanos são áreas importantes para mitigação das altas temperaturas.

Alba et al. (2017) estimaram a temperatura da superfície de áreas urbanas e rurais de Santa Maria, RS, para identificação de ilhas de calor por meio da análise da resposta espectral de alvos com imagens de satélite datadas de janeiro de 2014, e identificaram uma amplitude térmica de $18^{\circ} \mathrm{C}$, entre $26^{\circ} \mathrm{C}$ e $46^{\circ} \mathrm{C}$, com aumento da temperatura em áreas construídas. Aproximadamente $78 \%$ da área urbana apresentou temperatura moderada $\left(30^{\circ} \mathrm{C}\right.$ a $\left.36^{\circ} \mathrm{C}\right)$ e $28 \%$ temperatura alta (maior que $37^{\circ} \mathrm{C}$ ). Rovani et al. (2012) analisaram a formação ilhas de calor e frescor do bairro Camobi, em Santa Maria, por meio de transectos móveis com a medição de temperatura e umidade relativa do ar. Os autores também apontam para a influência do uso e ocupação do solo no clima urbano, identificando ilhas de calor e frescor com amplitude de $8^{\circ} \mathrm{C}$ e $-8^{\circ} \mathrm{C}$ respectivamente.

Santa Maria, objeto de análise neste artigo, não possui ainda nenhum estudo que a caracterize quanto às ZCL. Por Santa Maria se enquadrar como uma cidade de médio porte, com 285 mil habitantes, é possível se ter maior controle para a prevenção de microclimas desfavoráveis. Para isso, é preciso atrelar as ferramentas de planejamento urbano a medidas de sustentabilidade e recuperação de áreas já degradadas e a metodologia proposta por Stewart e Oke (2012) é fundamental nesse esforço.

Com base no método desenvolvido por Stewart e Oke (2012), o estudo apresentado neste artigo buscou contribuir para o entendimento e caracterização do clima urbano, sob os efeitos da urbanização, para a cidade de Santa Maria, RS. Com economia baseada principalmente no setor de

\begin{tabular}{lll}
\hline Zambonato e et al., 2021 & ISSN 0104-5490
\end{tabular}


comércio e serviços, o município apresenta taxas de crescimento positivas desde a década de 1950 (IBGE, 2020). Atualmente, mais de $95 \%$ da sua população reside em áreas urbanas (ADESM, 2020).

O trabalho, de caráter exploratório, foi desenvolvido por meio da análise de recortes urbanos que se caracterizam como áreas construídas densas. Busca-se descrever essas áreas segundo a classificação das ZCL, caracterizando-as por meio da reunião de informações e dados referentes às zonas climáticas encontradas. Analisa-se morfologicamente as áreas, seu comportamento e suas principais variáveis urbanísticas, as quais influenciam de forma mais significativa no microclima urbano.

\section{MÉTODO}

O método deste estudo foi composto por três etapas: definição das áreas de estudo, levantamento das variáveis de ocupação urbana e caracterização das áreas quanto ao percentual de superfícies de ocupação urbana e quanto à densidade construída. A classificação ZCL baseou-se na metodologia de Stewart e Oke (2012). Para este trabalho, foram definidas quatro áreas de estudo, com padrões de ocupação urbana distintos, localizadas na cidade de Santa Maria, RS.

\section{Definição das áreas de estudo}

Santa Maria pertence à região central do Rio Grande do Sul, com coordenadas geográficas 2941' de latitude sul e 5348' de longitude oeste (SARTORI, 1979), com altitude média de 155 metros. O município é o quinto do estado com maior número de habitantes, possui densidade demográfica de 160 hab/km2 e área igual a 1.782 km² (IBGE, 2019, ADESM, 2020). A área urbana do município corresponde a 6,82\% do território do município $(122 \mathrm{~km} 2)$ e concentra 95\% da população total do município. O Bairro Centro detém 7,25\% da população em uma área de 1,91 km2, com densidade demográfica de 10.700 hab/km2 (ADESM, 2020).

Os critérios de seleção das áreas foram: forma de ocupação pelas edificações, vegetação e tipos de pavimentos, densidade de ocupação e usos. As áreas selecionadas estão ilustradas na Figura 2. Localizam-se (a) no Bairro Nossa Senhora do Rosário, no encontro das ruas Visconde de Pelotas com Lucídio Gotan; (b) no Bairro Bonfim, no encontro das ruas Conde de Porto Alegre com Venâncio Aires; (c) no Bairro Centro, no encontro das ruas Floriano Peixoto com Dr. Bozano; e (d) 
no Bairro Camobi, no Conjunto Habitacional Fernando Ferrari, no encontro das ruas Dezesseis com Robison Flores. A escolha das áreas foi feita por meio de análise da imagem aérea e visitas a campo.

FIGURA II - IMAGEM AÉREA DAS ÁREAS DE ESTUDO SELECIONADAS.

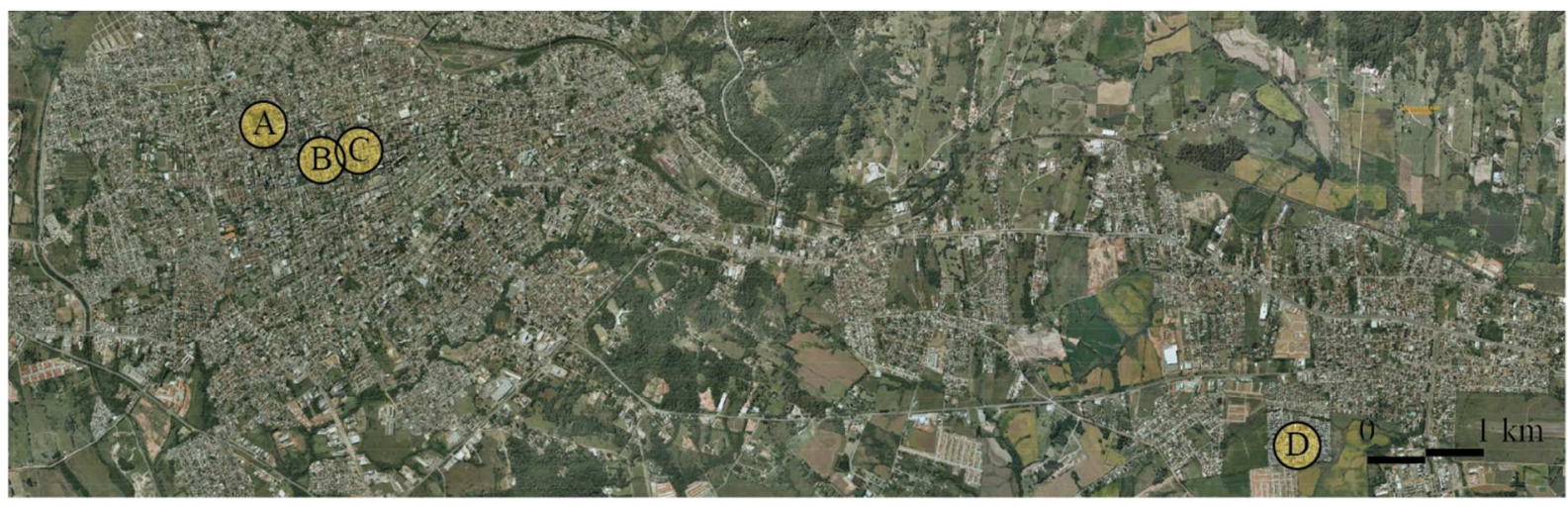

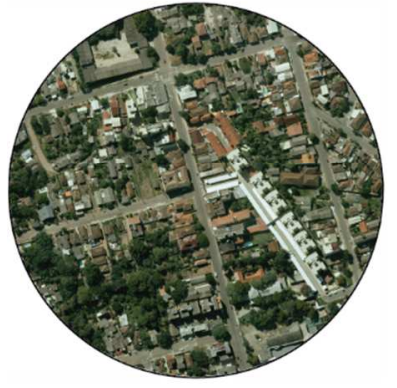

$\mathrm{A}(\mathrm{RO})$

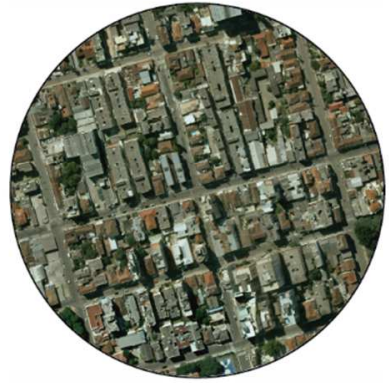

$\mathrm{B}(\mathrm{BO})$

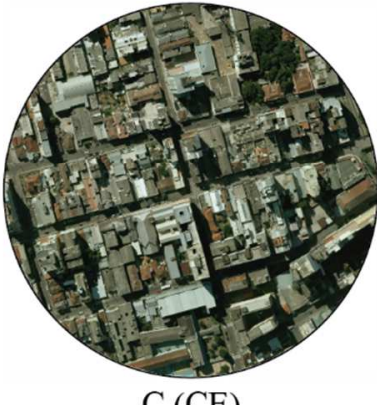

$\mathrm{C}(\mathrm{CE})$

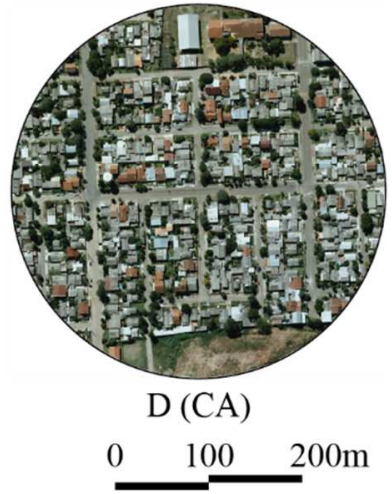

Fonte: Adaptado de IPLAN-SM (2015)

As análises foram limitadas a um círculo de raio $200 \mathrm{~m}$ a partir do encontro das vias citadas acima. A definição do raio de abrangência teve como base a metodologia de Stewart e Oke (2012), que sugere um diâmetro mínimo de $400 \mathrm{~m}$ para classificação da zona climática local.

\section{Levantamento das áreas}

Para cada área analisada, dentro do círculo com raio $200 \mathrm{~m}$, foram levantadas as seguintes variáveis: área de projeção das edificações, áreas pavimentadas (asfalto, concreto ou pedra), áreas gramadas, áreas permeáveis não vegetadas (solo exposto ou brita), árvores e corpos d'água (GRIGOLETTI; LAZAROTTO, WOLLMNANN, 2018). O levantamento destas variáveis foi realizado por meio da interpretação de imagens da cobertura aerofotogramétrica da área urbana da cidade, oriundas do Mapa Base Urbano (julho de 2015) e fornecidas pelo Instituto de Planejamento de Santa Maria (IPLAN-SM). A espacialização (vetorização) das informações levantadas foi realizada em um programa de desenho digital. 
Durante o levantamento das áreas, foram seguidos os seguintes procedimentos de padronização:

- a representação gráfica das áreas analisadas foi considerada a partir dos elementos vistos em posição superior, por exemplo, áreas gramadas sob projeção de edificações foram computadas como edificações;

- para cálculo da densidade construída, foi tomada uma altura de pé-direito padrão (três metros), devido à dificuldade de levantar o dado para cada edificação;

- foi considerada a volumetria externa das edificações, arbitrando, por exemplo, dois pavimentos para pavilhões com pé direito duplo, ou seja, 6 metros de altura;

- os obstáculos visíveis presentes na imagem devido às emendas, sombras e distorções, que ocorreram principalmente para edificações com mais de 6 pavimentos, foram conferidos no local, sempre que possível, a fim de eliminar erros na informação;

- na análise das áreas, não foram quantificados elementos considerados pequenos, como, por exemplo, caminhos e calçadas em meio a gramados; arbustos e vegetação de pequeno porte; poços de ventilação das edificações, entre outros;

- árvores de pequeno porte foram consideradas como arborização apenas quando em conjuntos expressivos, caso contrário foram desconsideradas;

- as edificações com sete ou mais pavimentos receberam a mesma cor de legenda, porém, o número real de pavimentos foi considerado para o cálculo de densidade construída;

- fluxo de veículos estipulado de acordo com as categorias de vias propostas pelo Plano Diretor de Mobilidade Urbana da cidade (PDMU, 2014), sendo: baixo (vias locais e coletoras), regular (vias coletoras e arteriais) e elevado (vias arteriais e estruturais); e

- fluxo de pedestres com contagem in loco durante o percurso na área, sendo categorizados três níveis: baixo (de 1 a 5 pedestres), regular (de 5 a 10 pedestres) e elevado (acima de 10).

\section{Caracterização das áreas}

Após o levantamento e espacialização das variáveis de ocupação do solo de cada área de estudo, com a ajuda do programa de desenho digital, foram obtidas as áreas relativas a cada superfície 
(árvore, revestimento vegetal, pavimento, solo exposto, água e edificações). Devido a erros inerentes às imagens e sua resolução, compatibilizou-se a relação entre a área total do círculo de $200 \mathrm{~m}$ de raio e a área resultante da soma representativa de cada ocupação levantada. A partir daí, foram criados diagramas com o uso de uma legenda associada às ocupações consideradas no estudo. A Figura 3 ilustra a espacialização dos dados de cada tipo de superfície dentro da amostra.

\section{FIGURA III - EXEMPLO DE (A) DEFINIÇÃO DO RECORTE E (B) PERCENTUAL DE SUPERFÍCIES DE OCUPAÇÃO URBANA DA ZONA CLIMÁTICA LOCAL A (RO).}

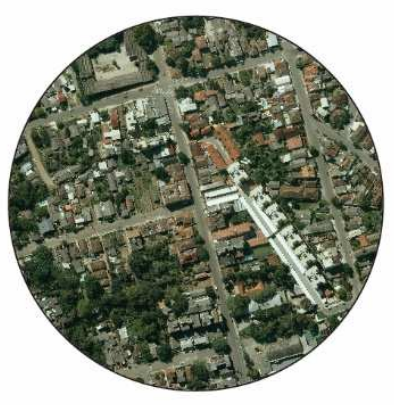

a

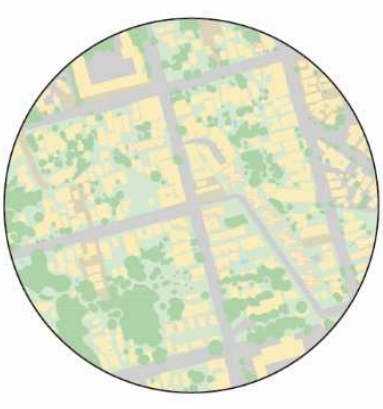

b legenda

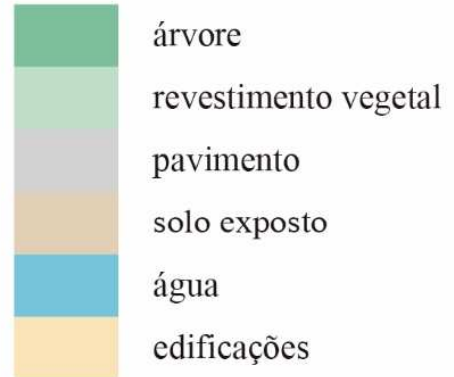

Fonte: Adaptado de IPLAN-SM (2015)

Por fim, foi calculada a densidade construída das áreas estudadas, considerando a quantidade de edificações por unidade de área bem como o número de pavimentos das edificações. Neste trabalho, a densidade construída foi considerada como a relação entre a área total construída na área de abrangência da amostra e a área total de superfície da amostra. Para isso, foi criada uma segunda legenda, diferenciando as edificações de acordo com o número de pavimentos (1, 2, 3, 4, 5, 6, 7 e mais de 7 pavimentos), por cor, como é ilustrado na Figura 4. Dessa forma foi possível calcular a área construída, multiplicando a área da projeção horizontal das edificações pelo número de pavimentos. 


\section{FIGURA IV - EXEMPLO DE (A) DEFINIÇÃO DO RECORTE E (B) DENSIDADE CONSTRUÍDA DA ZONA CLIMÁTICA LOCAL A (RO).}

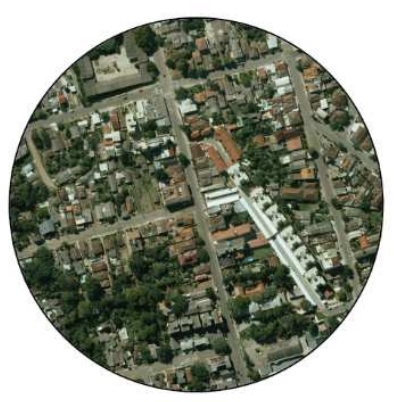

a

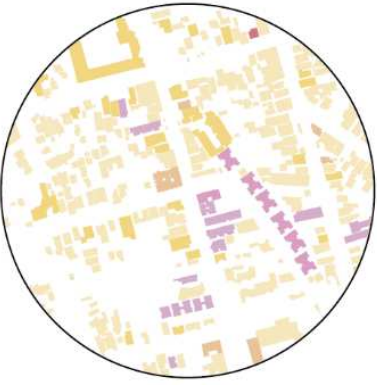

$\mathrm{b}$

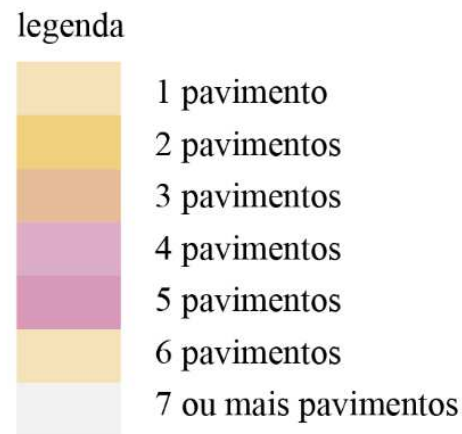

7 ou mais pavimentos

Fonte: Adaptado de IPLAN-SM (2015)

A partir desses dados, foi possível classificar as áreas de acordo com as ZCL propostas por Oke e Stewart (2012). Paralelamente, fez-se uma descrição de cada área a partir de observação direta, a fim de complementar os dados quantitativos.

\section{RESULTADOS}

A Tabela 1 apresenta a descrição das áreas estudadas, conforme levantamentos realizados, e a classificação da ZCL considerada para a área.

TABELA I - DESCRIÇÃO DAS ÁREAS ESTUDADAS

(continua)

\begin{tabular}{|l|l|}
\hline Imagem representativa & Descrição da área \\
\hline & $\begin{array}{l}\text { Local: A (RO). } \\
\text { Localização: encontro das ruas Visconde de Pelotas e Daut. } \\
\text { Características gerais: padrão construtivo predominantemente horizon- } \\
\text { tal, com edificações de 1 e 2 pavimentos isoladas no lote, e edificações } \\
\text { pontuais de até } 6 \text { pavimentos; elevada ocorrência de vegetação, geral- } \\
\text { mente em grandes maciços em áreas internas dos lotes. } \\
\text { Uso do solo: predominantemente residencial, havendo, em menor ocor- } \\
\text { rência, estabelecimentos comerciais e de serviços. } \\
\text { Vias: pavimentação predominantemente de asfalto, havendo algumas } \\
\text { vias sem pavimentação e sem calçada pavimentada. Fluxo regular de } \\
\text { veículos e baixo fluxo de pedestres, principalmente no período diurno. } \\
\text { ZCL: espaço aberto com edifícios baixos (ZCL 6). }\end{array}$ \\
\hline
\end{tabular}

Zambonato e et al., 2021

ISSN 0104-5490 


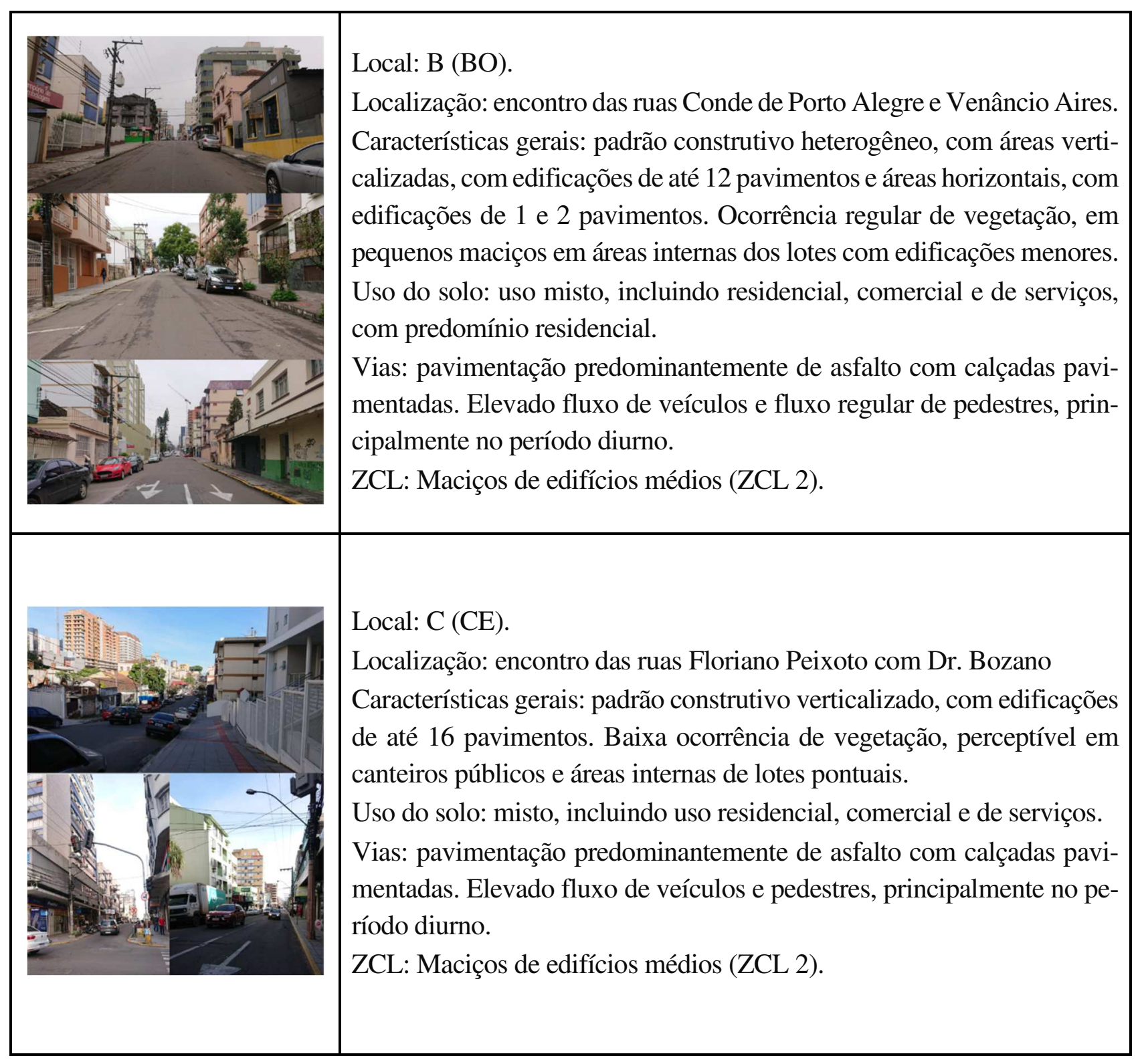




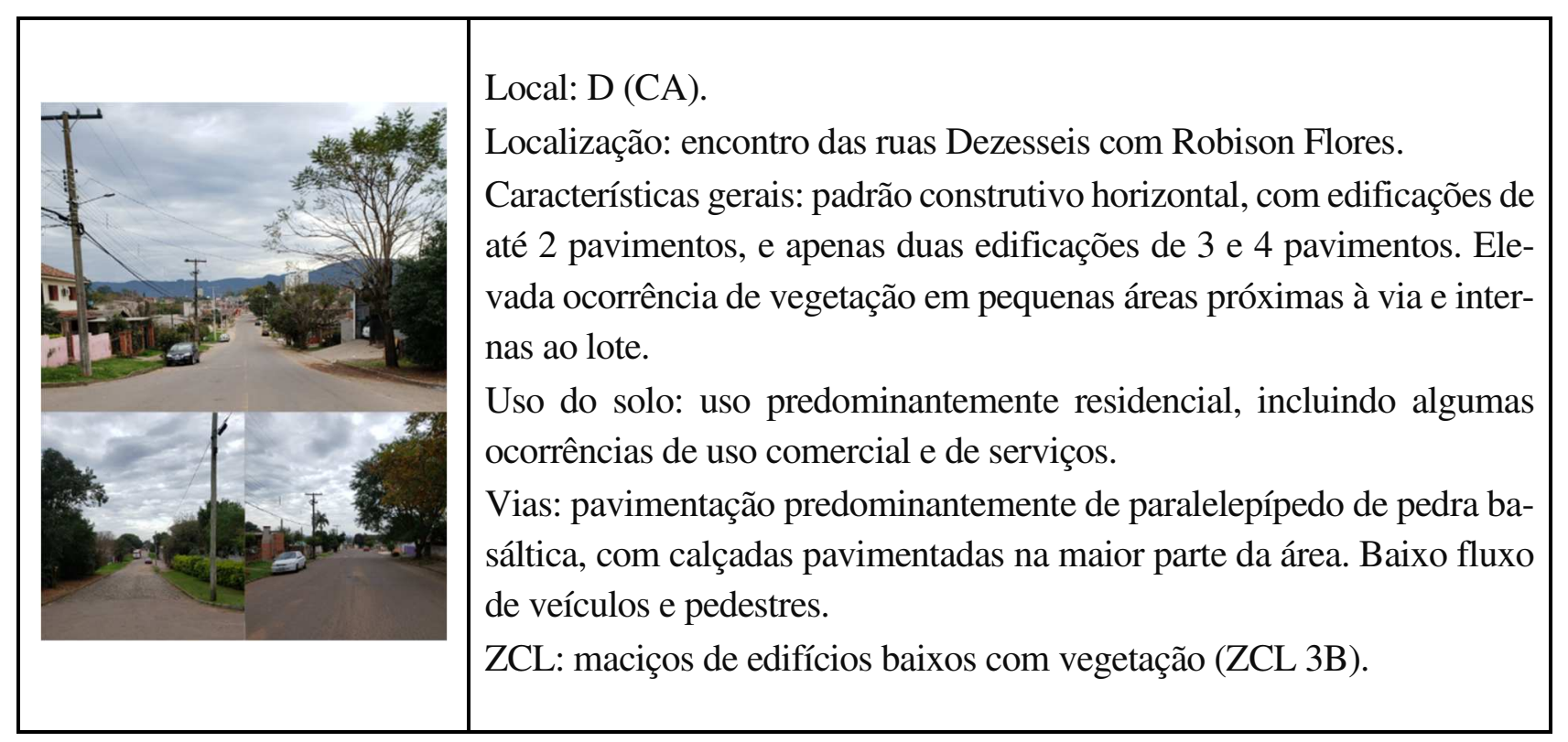

Fonte: Autoras, 2019

\section{Ocupação urbana}

A Figura 5 apresenta os resultados de ocupação urbana. Percebe-se que há diferenças significativas entre as regiões analisadas, confirmando que se caracterizam como ZCL distintas. Na região $\mathrm{A}(\mathrm{RO})$ as categorias de cobertura do solo predominantes foram edificações (30,08\%), apesar de ser a região com menor porcentagem de ocupação por essa categoria, seguido por revestimento vegetal $(28,35 \%)$. Na região B (BO), há a predominância de edificações $(46,80 \%)$ seguida de pavimento $(40,77 \%)$. Na região C (CE), foi identificada a maior ocupação por edificações $(60,99 \%)$, seguida de pavimento (30,19\%). Por fim, na região D (CA), as categorias de ocupação apresentaram distribuição mais uniforme. Ainda assim, houve predomínio de edificações $(33,19 \%)$ seguido de árvores $(19,01 \%)$. 
FIGURA V - SUPERFÍCIES DE OCUPAÇÃO DO SOLO NAS REGIÕES A (RO) (A), B (BO) (B), C (CE) (C) E $\mathrm{D}(\mathrm{CA})(\mathrm{D})$.

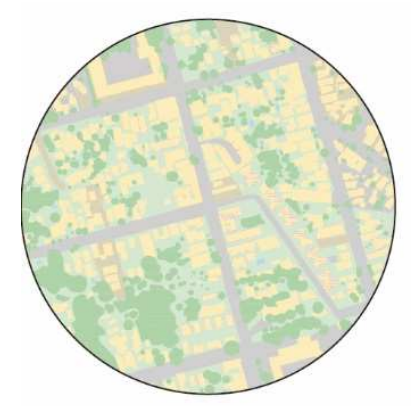

a

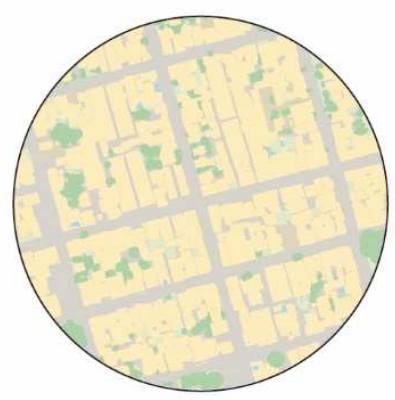

b

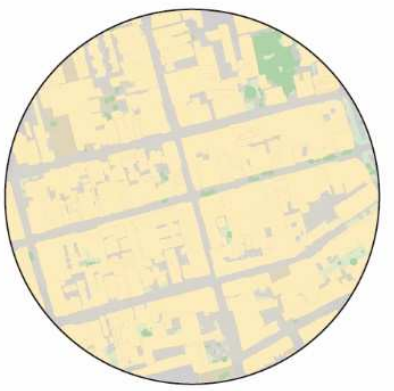

c

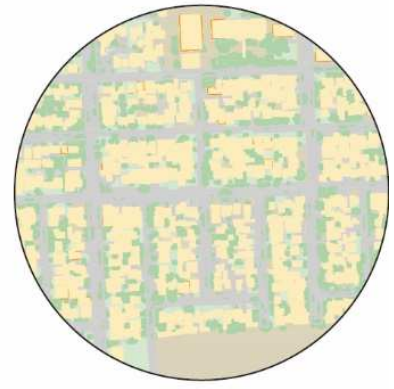

d

\begin{tabular}{l|c|c|c|c}
\multicolumn{1}{c|}{ categorias } & $\mathrm{A}(\mathrm{RO})(\%)$ & $\mathrm{B}(\mathrm{BO})(\%)$ & $\mathrm{C}(\mathrm{CE})(\%)$ & $\mathrm{D}(\mathrm{CA})(\%)$ \\
\hline árvore & 18,71 & 5,60 & 3,58 & 19,01 \\
\hline revestimento vegetal & 28,35 & 5,03 & 3,12 & 17,22 \\
\hline pavimento & 19,05 & 40,77 & 30,19 & 12,21 \\
\hline solo exposto & 3,70 & 1,68 & 2,07 & 18,35 \\
\hline água & 0,10 & 0,12 & 0,04 & 0,02 \\
\hline edificações & 30,08 & 46,80 & 60,99 & 33,19 \\
\hline
\end{tabular}

A região C (CE) está localizada no centro da cidade, em uma região predominantemente comercial, em que os lotes são ocupados quase na sua totalidade por edificações ou por áreas pavimentadas. Esta foi a região com menor porcentagem de áreas verdes (6,7\% somando árvores e revestimento vegetal). A região $\mathrm{B}(\mathrm{BO})$ também está localizada em uma região central, porém há predomínio de uso residencial, e alguns dos fundos de lote ainda preservam áreas verdes $(10,63 \%)$.

As regiões $\mathrm{A}(\mathrm{RO})$ e $\mathrm{D}(\mathrm{CA})$ são áreas predominantemente residenciais menos densas e afastadas do centro da cidade, com porcentagem de ocupação por edificações similar $(30,08 \%$ e $33,19 \%$, respectivamente). No entanto, ao analisar a distribuição de áreas verdes, percebe-se diferenças entre as duas regiões. A região A (RO) apresenta grandes áreas de vegetação, especialmente em fundo de lote e lotes ainda não ocupados. Se somadas, as porcentagens de árvores e revestimento vegetal $(47,06 \%)$ superam significativamente a cobertura de edificações $(30,08 \%)$.

Já a região D (CA) apresenta uma distribuição bastante homogênea entre as diferentes categorias. As áreas verdes, também significativas nesta região $(36,23 \%)$ são distribuídas por toda a 
área em pequenas porções, possivelmente resultado das dimensões dos lotes que são consideravelmente menores se comparados aos lotes das demais áreas de estudo. De modo geral, observa-se que há, na região A, relativamente próxima das regiões $\mathrm{B}$ e C, a presença significativa de vegetação. Essa característica se dá em decorrência de áreas vegetadas dentro dos lotes.

Para todas as áreas analisadas, destaca-se a irrisória porcentagem de superfície coberta por água, a qual tem o menor percentual e é representada, em sua maioria, por piscinas. Os corpos d'água são auxiliares na mitigação do clima, tais como córregos, riachos, lagos (SUN; CHEN, 2012). A cidade possui uma grande quantidade de pequenos corpos d'água, como os córregos que, no entanto, estão canalizados e sobrepostos por construções e vias, em sua grande maioria.

Considerando os benefícios da vegetação para a amenização dos extremos de temperatura diários (DUNCAN et al., 2019), o planejamento urbano deve prever ferramentas que incentivem a manutenção dessas áreas vegetadas, que, embora aqui tenha sido analisado apenas alguns recortes do tecido urbano, são recorrentes em vários bairros próximos ao centro. Dessa forma, uma vez que, devido à alta densidade construída do centro, não é possível inserir áreas vegetadas significativas, as áreas circundantes podem colaborar com o arrefecimento das altas temperaturas, principalmente, com a absorção de poluentes, dentre outros aspectos positivos relacionados à vegetação.

\section{Densidade construída}

Assim como as superfícies de ocupação urbana, a densidade construída das áreas de estudo revela diferenças entre as regiões estudadas. As regiões B (BO) e C (CE), centrais, apresentam densidade construída de 2 a 8 vezes maior que a densidade construída nas regiões A (RO) e D (CA). Este resultado reforça as características identificadas no levantamento das superfícies de ocupação urbana. A Figura 6, a seguir, apresenta os mapas de densidade construída das 4 regiões analisadas, mostrando a diferença de altura das edificações. É também apresentada a porcentagem de área construída - que foi calculada considerando a projeção horizontal das diferentes alturas em relação ao total de área edificada (total de edificações) - bem como a densidade construída de cada região, calculada de acordo com o método apresentado no item 2.3 . 
FIGURA VI - DENSIDADE CONSTRUÍDA DE OCUPAÇÃO DO SOLO NAS REGIÕES A (RO) (A), B (BO) (B), C (CE) (C) E D (CA) (D).

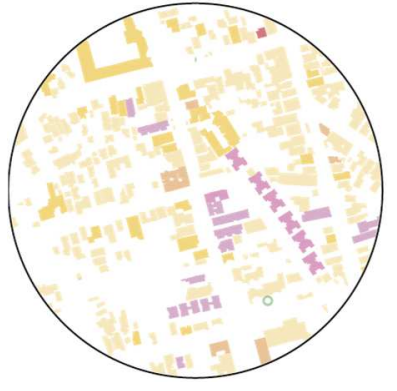

a

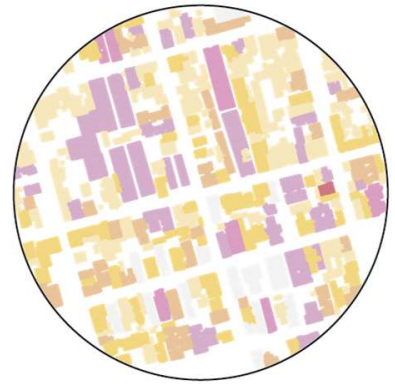

b

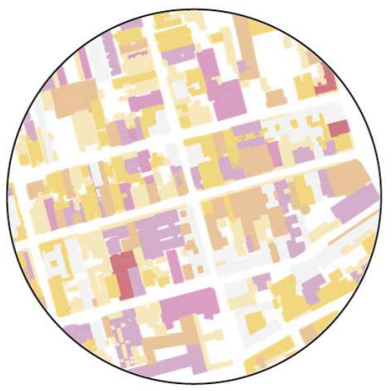

c

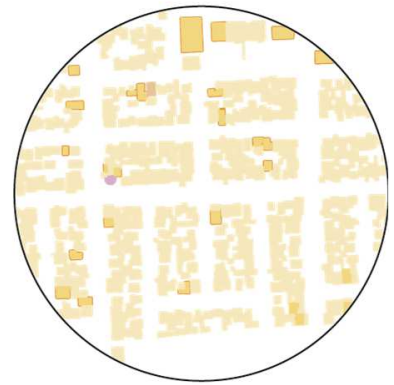

d

\begin{tabular}{l|c|c|c|c} 
número de pavimentos & $\mathrm{A}(\mathrm{RO})(\%)$ & $\mathrm{B}(\mathrm{BO})(\%)$ & $\mathrm{C}(\mathrm{CE})(\%)$ & $\mathrm{D}(\mathrm{CA})(\%)$ \\
\hline 1 pavimento & 66,12 & 28,57 & 19,86 & 87,74 \\
\hline 2 pavimentos & 18,30 & 21,35 & 18,77 & 11,53 \\
\hline 3 pavimentos & 3,57 & 13,67 & 16,27 & 0,41 \\
\hline 4 pavimentos & 7,38 & 22,04 & 16,93 & 0,32 \\
\hline 5 pavimentos & 4,41 & 5,34 & 7,67 & 0,00 \\
\hline 6 pavimentos & 0,23 & 0,30 & 2,03 & 0,00 \\
\hline 7 ou mais pavimentos & 0,00 & 8,74 & 18,48 & 0,00 \\
\hline densidade construída & 50,03 & 144,15 & 265,04 & 33,19 \\
\hline
\end{tabular}

A região com maior densidade (265,04\%), C (CE), é composta principalmente por edificações com 4 ou mais pavimentos $(45,11 \%)$, caracterizando-se como uma zona densamente construída e com edificações predominantemente altas. Esta característica pode causar grande impacto no microclima urbano da área, como o aumento da temperatura, redução da umidade do ar, aumento da velocidade do vento devido aos corredores de vento formado pelas edificações e mudança na direção dos ventos (LUZ et al., 2015).

A região B (BO), também apresenta densidade elevada (144,15\%), no entanto a porcentagem de edificações com 4 pavimentos ou mais $(36,42 \%)$ é menor do que na região C (CE). Duas quadras da área analisada concentram a maior parte das edificações acima de 4 pavimentos, onde os efeitos do ambiente construído no microclima urbano provavelmente são mais acentuados, enquanto as demais quadras são compostas por edificações baixas, contribuindo para amenizar tais efeitos. É importante destacar que a maior parte das edificações baixas existentes nesta região são 
habitações antigas, sendo que algumas delas já começaram a ser substituídas por novas edificações altas que ocupam a maior parte do lote. Sendo assim, é possível que o microclima desta região venha a sofrer mais alterações em decorrência da construção de novas edificações, caso não haja revisão da legislação urbana vigente considerando temas como o microclima urbano, eficiência energética de edificações e o conforto ambiental em espaços livres.

As regiões A (RO) e D (CA) apresentam baixas densidades (50,03\% e 33,19\%, respectivamente), com predominância de edificações de 1 e 2 pavimentos. Nestas regiões é possível que os efeitos do ambiente construído contribuam para um microclima mais ameno (LUZ et al., 2015). Por estar localizada em uma região mais próxima do centro da cidade, a região A (RO) ainda apresenta pontuais edificações com mais de 4 pavimentos (12,02\%). São edificações como, por exemplo, condomínio residencial formado por 6 edificações de 4 pavimentos, e alguns edifícios residenciais de 4 ou mais pavimentos, concentrados, principalmente em uma mesma rua. Acredita-se que pela baixa concentração destas edificações, seus efeitos não sejam significativamente percebidos no microclima.

Por fim, a região D (CA) apresentou a menor densidade construída entre as regiões analisadas $(33,19 \%)$. A região é formada por quadras e lotes menores, se comparado com as demais regiões analisadas, pois foi idealizada inicialmente como um loteamento construído pelo projeto de Companhias de Habitação Popular (COHAB), no ano de 1982 (RUBIM, 2013). Pela dimensão dos lotes e pelo caráter predominantemente residencial, a região é composta por edificações de 1 e 2 pavimentos (99,27\%), havendo apenas uma edificação de 3 pavimentos e uma de 4 pavimentos, a qual abriga o reservatório de água que abastece a região. É possível que os efeitos do ambiente construído no microclima sejam moderados ou pouco perceptíveis na região, devido à baixa densidade construída.

Através da análise da densidade construída, nota-se que a cidade de Santa Maria ainda não possui uma verticalização acentuada. Aspecto que se entende positivo, já que permite que se faça um planejamento urbano que mescle áreas mais densas e verticalizadas com áreas menos densas, permeadas com áreas vegetadas. $\mathrm{O}$ atual plano diretor do município possui uma diretriz para verticalização do que chama de corredores de urbanidade (ao longo das principais vias da cidade). No entanto, essa interpretação requer incluir outros aspectos que não são considerados, uma vez que 
essa abordagem poderá eliminar áreas potencialmente mitigadoras dos climas extremos, já que a região é caracterizada por verões muito quentes e invernos relativamente rigorosos.

A identificação das informações da superfície urbana nas imagens aerofotogramétricas e sua associação com o mapeamento de padrões paisagísticos permite entender as diferentes influências desses padrões nas condições locais do clima. Posterior a esse entendimento, é possível relacionar a morfologia da superfície e a cobertura do solo com as diferenças de temperaturas do ar entre as unidades, uma próxima etapa deste estudo.

Os estudos de Rocha, Souza e Castilho (2011), para São José do Rio Preto, Santos (2013), para Cuiabá, Cardoso e Amorim (2014), para Presidente Prudente, todas cidades de porte similar à Santa Maria, bem como os estudos para cidades de pequeno porte, como os de Brússolo e Ely (2015) e Alves e Specian (2010), e com os mesmos problemas decorrentes de sua urbanização, como a pavimentação excessiva do solo, a remoção da cobertura arbórea, a canalização dos corpos de água, apontaram a importância do uso e ocupação do solo na conformação de microclimas urbanos e ilhas de calor. Apesar de não haver medições das temperaturas nas ZCLs caracterizadas para Santa Maria, os estudos citados indicam que as áreas mais pavimentadas e densamente construídas, com pouca cobertura arbórea, apresentam temperaturas mais altas no verão.

A análise das ZCLs pode colaborar com o planejamento urbano visando a manutenção de características de certas regiões da cidade como miolos de quarteirão ainda com espécies arbóreas que auxiliarão com o arrefecimento local das temperaturas e vazios urbanos, ainda vegetados, que podem contribuir com a melhoria do clima urbano do ponto de vista do controle de altas temperaturas. Além disso, a análise das ZCLs pode colaborar para diretrizes de pavimentação das vias públicas, por meio de diretrizes de adoção de pavimentos claros e que mantenham certa permeabilidade, além de outros recursos como biovaletas e canteiros arborizados nos passeios, para aquelas regiões da cidade em que não é mais possível contar com a vegetação original, com o objetivo de criar microclimas urbanos mais aceitáveis, tanto do ponto de vista do pedestre quanto do ponto de vista do próprio consumo energético das edificações. 


\section{CONSIDERAÇÕES FINAIS}

O objetivo do estudo de mapear, descrever e classificar elementos da morfologia urbana, de quatro recortes distintos da cidade de Santa Maria, RS, foi o primeiro passo para a classificação das paisagens naturais e urbanas em categorias, para então, posteriormente, compreender as propriedades significativas em relação ao clima local.

O trabalho colaborou com este objetivo, fundamental para identificação das características que possam influenciar no microclima formando ilhas de calor. Os resultados obtidos demonstraram uma variação significativa quanto ao percentual de superfícies de ocupação urbana e quanto à densidade construída nas áreas. Como já previsto, há relação direta entre a proporção de vegetação e edificações, pois as zonas com maior superfície vegetal (revestimento vegetal e árvores) apresentaram menor porcentagem de edificações, e zonas com menor número de superfície vegetal apresentaram maior porcentagem de área edificada.

Já quanto à densidade construída, notou-se que, quanto mais afastada do centro, menor torna-se essa porcentagem. No exemplo analisado, é possível relacionar esse resultado ao planejamento urbano, pois a área que apresenta menor densidade construída - D (CA) com 33,19\% - é residencial e fruto de um loteamento planejado, organizado em terreno de topografia plana e afastado do centro. Bastante comum em outras cidades, as áreas centrais sofrem grande especulação imobiliária e, consequentemente, há grande valorização do solo urbano, contribuindo para o aumento da densidade construída nessas regiões, acarretando consequências refletidas diretamente, entre outros, no microclima urbano.

No decorrer do estudo, apresentaram-se dificuldades em relação à coleta de algumas informações espaciais. A qualidade da imagem aérea não permitiu a identificação de coberturas de solo em determinados fundos de lotes. Também, a imagem apresentou áreas sombreadas e algumas distorções. Entretanto, ao realizar-se o levantamento in loco as dúvidas possíveis de verificação foram sanadas, embora ainda existam espaços sem alcance para aferição.

Apesar das dificuldades, os resultados obtidos permitiram que se conseguisse realizar a pesquisa e contribuir para a classificação das zonas climáticas na cidade de Santa Maria, RS. Esperase que com os dados adquiridos novos estudos auxiliem na classificação das zonas climáticas, possibilitando maior entendimento dos efeitos das Ilhas de Calor e facilitando a sugestão de medidas e estratégias que melhorem as condições locais do clima desses espaços.

\begin{tabular}{lll}
\hline Zambonato e et al., 2021 & 103
\end{tabular}




\section{AGRADECIMENTOS}

Agradecemos ao Instituto de Planejamento de Santa Maria (IPLAN-SM), pelo fornecimento de imagens da cobertura aerofotogramétrica da área urbana da cidade e à Coordenação de Aperfeiçoamento de Pessoal de Nível Superior (CAPES) - Código de financiamento 001 pela concessão de bolsas de mestrado.

\section{REFERÊNCIAS}

ADESM. Agência de Desenvolvimento de Santa Maria. Santa Maria em Dados. Demografia. Santa Maria, ADESM, 2020. Disponível em: http://santamariaemdados.com.br/sociedade/8-1demografia/. Acesso em: 08 abr. 2020.

ALBA, E.; MARCHSAN, J.; SILVA, E. A; MELLO, E. P.; PEDRALI, L. D.; PEREIRA, R. S. Identificação de ilhas de calor e sua relação com a fisionomia da paisagem. In: Simpósio Internacional SELPER, 17., 2016, Puerto Iguazú. Anais [...]. Lújan: EdUnLu, 2017, p. 429438.

ALVES, E. D.; SPECIAN, V. O clima intra-urbano de Iporá- GO: um estudo em episódios. Revista de Geografia (UFPE), p. 141-154, 2010.

AMORIM, M. C. de C. T. Climatologia e gestão do espaço urbano. Mercator, v. 9, p. 71-90, 2010.

AMORIM, M. C. de C. T. O clima urbano de Presidente Prudente/SP. 2000. Tese (Doutorado em Geografia Física) - Universidade de São Paulo, São Paulo, 2000.

BECHTEL, B.; ALEXANDER, P. J.; BÖHNER, J.; CHING, J.; CONRAD, O.; FEDDEMA, J.; MILLS, G.; SEE, L.; STEWART, I. Mapping Local Climate Zones for a worldwide database of the forma and function of cities. ISPRS Int. J. of Geo-Inf., v. 4, p. 199-219, 2015.

BÚSSOLO, R. G.; ELY, D. F. O clima e a cidade: ilhas de calor em Assis (SP). Revista Formação, n. 22, v. 2, p. 99-127, 2015.

CARDOSO, R. dos S.; AMORIM, M. C. de C. T. Características do clima urbano em Presidente Prudente/SP a partir de dados de temperature e umidade relativa do ar e técnicas de sensoriamento remoto. Revista do Departamento de Geografia - USP, v. 28, p. 39-64, 2014.

DANYLO, O.; SEE, L.; BECHTEL, B.; SCHEPASCHENKO, D.; FRITZ, S. Contributing to WUDAPT; a Local Climate Zone classification of two cities in Ukraine. IEEE J. Sel. Top. Appl. Earth Obs. Remote Sens., v. 9, n. 5, p. 1.841-1.853, 2016. 
DUARTE, D. H. S.; SHINZATO, C. dos S. G.; ALVES, C. A. The impact of vegetation on urban microclimate to counterbalance built density in a subtropical changing climate. Urban Climate, v. 14, n. 2, p. 224-239, 2015.

DUMKE, C. de A. L. Clima urbano, conforto térmico e condições de vida na cidade: uma perspectiva a partir do aglomerado urbano da Região Metropolitana de Curitiba (AURMC). 2007. Tese (Doutorado em Meio Ambiente e Desenvolvimento) - Universidade Federal do Paraná, Curitiba, 2007.

DUNCAN, J. M. A.; BORUFF, B.; SAUNDERS, A.; SUN, Q.; HURLEY, J.; AMATI, M. Turning down the heat: an enhanced understanding of the relationship between urban vegetation and surface temperature at the city scale. Sci. Total Environ., v. 656, p. 118-128, 2019.

EMBRAPA. Empresa Brasileira de Pesquisa Agropecuária. Notícias: Mais de 80\% da população brasileira habita $0,63 \%$ do território nacional. EMBRAPA, Gestão Ambiental e Territorial, notícia veiculada em 10 out. 2017. Disponível em: https://www.embrapa.br/busca-de-noticias/-/noticia/28840923/mais-de-80-da-populacao-brasileira-habita-063-do-territorio-nacional. Acesso em: 08 abr. 2020.

FIALHO, E. S.; CELESTINO, E. J.; QUINA, R. R. O campo térmico em situação episódica de primavera em uma cidade de pequeno porte na Zona da Mata mineira: um estudo de caso em Cajuri - MG. Revista de Geografia (Recife), v. 33, n. 4, p. 299-318, 2016.

FIALHO, E. S.; FERNANDES, L. A.; CORREA, W. de S. C. Climatologia urbana: conceitos, metodologias e técnicas. Revista Brasileira de Climatologia, Ano 15, Edição Especial, XXIII Simpósio Brasileiro de Climatologia Geográfica, jun., 2019.

GRIGOLETTI, G. de C.; LAZAROTTO, G.; WOLLMANN, C. A. Microclima urbano de áreas residenciais no período noturno: estudo em Santa Maria, RS. Sociedade \& Natureza, v. 30, n. 2, p. 140-163, 2018.

IBGE. Instituto Brasileiro de Geografia e Estatística. População Rural e Urbana. IBGE Educa Jovens. 2020. Disponível em: https://educa.ibge.gov.br/jovens/conheca-o-brasil/populacao/18313-populacao-rural-e-urbana.html. Acesso em: 08 abr. 2020.

IPLAN. Instituto de Planejamento de Santa Maria, RS. Imagem fotogramétrica. Santa Maria, 2015.

LOMBARDO, M. A. Ilha de calor nas metrópoles: o exemplo de São Paulo. São Paulo: Hucitec, 1985.

LUZ, V. de S; MACIEL, C. de R.; SANTOS, F. M. de M.; NOGUEIRA, M. C. de J. A.; NOGUEIRA, J. de S. Influência da cobertura do solo urbano nas variáveis microclimáticas na cidade de Cuiabá-MT-Brasil. In: Encontro Nacional e Latino-Americano de conforto no Ambiente Construído, 13. e 9., 2015. Anais [...]. Campinas: ANTAC, 2015. 
MASIERO, E.; SOUSA, L. C. Clima urbano e estabelecimento de diretrizes para cenários de ocupação do solo. Cadernos Zysmunt Bauman, v. 8, n. 18, p. 1-13, 2018.

MENDONÇA, F. de A. O clima e o planejamento urbano das cidades de porte médio e pequeno: proposições metodológicas para estudo e sua aplicação à cidade de Londrina/PR. 1994. Tese (Doutorado em Geografia Física) - Universidade de São Paulo, São Paulo, 1994.

MIRZAEI, P.A. Recent challenges in modelling of urban heat island. Sustainable Cities and Society, v. 19, p. 200-206, 2015.

NUCCI, J. C. Qualidade ambiental e adensamento urbano: um estudo de ecologia e planejamento da paisagem aplicado ao distrito de Santa Cecília (MSP). 2. ed. Curitiba: edição do autor, 2008. Disponível em: https://tgpusp.files.wordpress.com/2018/05/qualidade-ambiental-e-adensamento-urbano-nucci-2008.pdf. Acesso em: 08 abr. 2020.

OKE, T. R. Boundary Layer Climates. 2. ed. London: Methuen \& Co., 1987.

OKE, T. R. Initial guidance to obtain representative meteorological observations at urban sites. IOM Report 81, WMO/TD, n. 1250.World Meteorological Organization: Geneva, 2006. Disponível em: https://library.wmo.int/doc_num.php?explnum_id=9286. Acesso em: 08 abr. 2020.

PITTON, S. E. C. As cidades como indicadores de alterações térmicas. 1997. Tese (Doutorado em Geografia Física) - Universidade de São Paulo, São Paulo, 1997.

ROCHA, L. M. V.; SOUZA, L. C. L.; CASTILHO, F. J. V. Ocupação do solo e ilha de calor noturna em avenidas marginais a um córrego urbano. Ambiente Construído, v. 11, n. 3, p.161-175, 2011.

ROSSI, F. A.; KRÜGER, E. L. Análise da variação de temperaturas locais em função das características de ocupação do solo em Curitiba. RAEGA: O Espaço Geográfico em Análise, n. 10, p. 93-105, 2005.

ROVANI, F. M.; RODRIGUES, E. C.; SARTORI, M. D. B.; CASSOL, R. Ilhas de calor e frescor urbanas no bairro Camobi, Santa Maria/RS, um dia sob domínio da massa polar velha ou modificada na primavera. Revista Brasileira de Climatologia, v. 10, p. 21-29, 2012.

RUBIM, G. R. Análise dos Programas Habitacionais em Santa Maria: O Caso do Conjunto Habitacional Tancredo Neves. 2013. Dissertação (Mestrado em Geografia e Geociências) - Universidade Federal de Santa Maria, 2013.

SANTOS, F. M. de M. Clima urbano de Cuiabá - MT - Brasil: ocupação do solo e suas influências. Revista Monografias Ambientais - REMOA, v. 12, n. 12, p. 2.749-2.763, 2013. 
SANTOS, J. G. R. dos. Variação higrotérmica urbana de Goiânia/GO em um mês de calor intenso. Revista Brasileira de Climatologia, ano 16, v. 17, p. 241-270, 2020.

SARTORI, M. da G. B. Considerações sobre a ventilação nas cidades e sua importância no planejamento urbano. Ciência \& Natura, Santa Maria, n. 6, p. 59-74, 1984.

STEWART, I. D.; OKE, T. R. Classifying urban climate field sites by "local climate zones": the case of Nagano, Japan. In: International Conference on Urban Climate, 7., 2009, Yokohama. Anais [...]. Yokohama: International Association for Urban Climate (IAUC), 2009.

STEWART, I. D.; OKE, T. R. Local climate zones for urban temperature studies. Bull. Am. Meteorol. Soc., December, 2012. Disponível em: https://journals.ametsoc.org/doi/full/10.1175/BAMS-D-11-00019.1. Accessed in: April $8^{\text {th }}$ of 2020.

SUN, R.; CHEN, L. How can urban water bodies be designed for climate adaptation?

Landsc. Urban Plan., v. 105, n. 1-2, p. 27-33, 2012.

TARIFA, J. R. Análise comparativa da temperatura e umidade na área urbana e rural de São José dos Campos (SP). Geografia, v. 2, n. 4, p. 59-80, outubro, 1977.

UGEDA JÚNIOR, J. C. Clima urbano e planejamento na cidade de Jales/SP. 2012. Tese (Doutorado em Geografia) - Universidade Estadual Paulista, Presidente Prudente, 2012.

UN. United Nations. World Urbanization Prospects: the 2018 revision. New York: United Nations, 2019.

WANG, R.; REN, C.; XU, Y.; LAU, K. K.; SHI, Y. Mapping the local climate zones of urban areas by GIS-based and WUDAPT methods: A case study of Hong Kong. Urban Climate, v. 24, p. 567-576, 2018. 